\title{
A novel serogenetic approach determines the community prevalence of celiac disease and informs improved diagnostic pathways
}

Robert P Anderson 1,2,3,4* , Margaret J Henry ${ }^{5}$, Roberta Taylor ${ }^{6}$, Emma L Duncan 7,8 , Patrick Danoy ${ }^{7,12}$, Marylia J Costa ${ }^{1,2}$, Kathryn Addison ${ }^{7}$, Jason A Tye-Din ${ }^{1,2,3}$, Mark A Kotowicz ${ }^{5,9}$, Ross E Knight ${ }^{10}$, Wendy Pollock ${ }^{6}$, Geoffrey C Nicholson ${ }^{8,11}$, Ban-Hock Toh ${ }^{6}$, Matthew A Brown ${ }^{7}$ and Julie A Pasco 5,9

\begin{abstract}
Background: Changing perspectives on the natural history of celiac disease (CD), new serology and genetic tests, and amended histological criteria for diagnosis cast doubt on past prevalence estimates for CD. We set out to establish a more accurate prevalence estimate for $C D$ using a novel serogenetic approach.

Methods: The human leukocyte antigen (HLA)-DQ genotype was determined in 356 patients with 'biopsy-confirmed' $C D$, and in two age-stratified, randomly selected community cohorts of 1,390 women and 1,158 men. Sera were screened for CD-specific serology.

Results: Only five 'biopsy-confirmed' patients with CD did not possess the susceptibility alleles HLA-DQ2.5, DQ8, or DQ2.2, and four of these were misdiagnoses. HLA-DQ2.5, DQ8, or DQ2.2 was present in 56\% of all women and men in the community cohorts. Transglutaminase (TG)-2 IgA and composite TG2/deamidated gliadin peptide (DGP) IgA/ IgG were abnormal in $4.6 \%$ and $5.6 \%$, respectively, of the community women and $6.9 \%$ and $6.9 \%$, respectively, of the community men, but in the screen-positive group, only $71 \%$ and $75 \%$, respectively, of women and $65 \%$ and $63 \%$, respectively, of men possessed HLA-DQ2.5, DQ8, or DQ2.2. Medical review was possible for $41 \%$ of seropositive women and 50\% of seropositive men, and led to biopsy-confirmed CD in 10 women (0.7\%) and 6 men (0.5\%), but based on relative risk for HLA-DQ2.5, DQ8, or DQ2.2 in all TG2 IgA or TG2/DGP IgA/lgG screen-positive subjects, CD affected $1.3 \%$ or $1.9 \%$, respectively, of females and $1.3 \%$ or $1.2 \%$, respectively, of men. Serogenetic data from these community cohorts indicated that testing screen positives for HLA-DQ, or carrying out HLA-DQ and further serology, could have reduced unnecessary gastroscopies due to false-positive serology by at least $40 \%$ and by over $70 \%$, respectively.
\end{abstract}

Conclusions: Screening with TG2 IgA serology and requiring biopsy confirmation caused the community prevalence of CD to be substantially underestimated. Testing for HLA-DQ genes and confirmatory serology could reduce the numbers of unnecessary gastroscopies.

Keywords: Celiac disease, Diagnosis, Epidemiology, Serology, Transglutaminase, Deamidated gliadin peptide, Immunogenetics, Prevalence

\footnotetext{
* Correspondence: bob@immusant.com

${ }^{1}$ The Walter and Eliza Hall Institute of Medical Research, 1G Royal Parade,

Parkville, Victoria 3052, Australia

${ }^{2}$ Department of Medical Biology, The University of Melbourne, Parkville,

Victoria 3010, Australia

Full list of author information is available at the end of the article
} 


\section{Background}

It is not uncommon for patients suspected of having celiac disease $(\mathrm{CD})$ to be reluctant to undergo definitive testing by small bowel biopsy. By contrast, an online community survey of randomly selected Australians indicated that $28 \%$ of adults monitor their dietary gluten intake, with $4 \%$ avoiding it altogether, $5 \%$ strictly controlling intake, and a further 18\% loosely controlling consumption (Coeliac Australia, personal communication). Despite the current popularity of gluten-free food, it is unclear what proportion of the community with $C D$ is diagnosed or remains unrecognized $[1,2]$.

Over the past 20 years or more, widely implemented expert guidelines have recommended that diagnosis of CD should be based on small bowel histology showing villous atrophy and confirmed by symptoms, laboratory abnormalities, and/or intestinal histology showing improvement with exclusion of dietary gluten [3]. However, several developments have challenged this definition. Recently the European Society for Pediatric Gastroenterology, Hepatology, and Nutrition (ESPGHAN) Working Group on Coeliac Disease Diagnosis proposed that CD should be redefined as an immune-mediated systemic disorder elicited by gluten and related prolamines in genetically susceptible individuals, characterized by the presence of a variable combination of gluten-dependent clinical manifestations, CD-specific antibodies, human leukocyte antigen (HLA)-DQ2 and HLA-DQ8 haplotypes, and enteropathy' [4]. The ESPGHAN Working Group also concluded $\mathrm{CD}$ is frequently difficult to recognize 'because of the variation in presentation and intensity of symptoms and signs, and many cases may actually occur without symptoms' [4]. Consequently, a new approach to the diagnosis of $\mathrm{CD}$ has recently been published, in which for the first time, HLA-DQ genotyping was included as the initial step in testing for $C D$ in patients who are considered at risk of $\mathrm{CD}$, but do not have the typical symptoms. In many countries with sophisticated healthcare such as the USA and most of Europe, by far the majority of patients with $\mathrm{CD}$ in the community remain undiagnosed and do not present to their physicians with the so-called 'typical' digestive symptoms. However, patients presenting in primary care and in many sub-specialty clinics frequently have symptoms and co-morbidities that raise the possibility of $\mathrm{CD}$, or might have adopted a gluten-free diet without prior assessment for $\mathrm{CD}$ [5]. Even if physicians were more aware of the diverse clinical presentations of $C D$ and the availability of new serological and genetic tests, it is not yet clear how to efficiently and cost-effectively assess the possibility of $\mathrm{CD}$ in patients without typical gastrointestinal symptoms.

Almost all credible community prevalence studies for $\mathrm{CD}$ have relied on sera being initially screened by 'CD- specific serology', followed by additional supportive serology or 'definitive' intestinal histology showing villous atrophy [2]. However, the frequencies of false-positive and false-negative IgA endomysial immunofluorescence (EMA) and tissue transglutaminase (TG)-2 serology assays can vary widely. In part, this uncertainty arises because abnormal intestinal histology remains the gold standard for diagnosis. In community prevalence studies, there is the practical problem that many subjects are unable or refuse to have gastroscopies to allow intestinal histology to be ascertained. A further issue is what constitutes abnormal histology compatible with CD, particularly if only mild inflammation showing increased density of intra-epithelial lymphocytes (IELs) is found without evidence of villous atrophy [1,6-10].

The first $C D$ prevalence studies from Australia highlight these challenges $[11,12]$. Based on a single set of sera collected 5 years earlier, 10 of 3,011 adults were found to be positive for EMA, and all 7 who underwent gastroscopy were confirmed by intestinal histology as having $\mathrm{CD}$, thus when 2 cases already diagnosed based on biopsy were combined with those found by screening, the estimated prevalence of $\mathrm{CD}$ was $0.4 \%$. In a follow-up study 5 years later, using the same serum set, TG2 IgA or IgG serology was found to be raised in 47 sera, and CD was confirmed after intestinal histology in 14 of 31 seropositive subjects available for follow-up [11]. Thus, the investigators offered a revised prevalence estimate of at least $0.56 \%$ based on histology-confirmed cases, but proposed that the rate of affected subjects could be as high as $0.96 \%$ if other seropositive subjects who carried HLA-DQ2 or DQ8 were also included.

An outstanding feature of $C D$ is that almost all affected individuals possess immune recognition genes encoding either HLA-DQ2.5, DQ8, or DQ2.2, which facilitate CD4 T-cell recognition of specific gluten-derived peptides [13-17]. HLA typing for DQ2.5, DQ8, and/or DQ2.2 is an exceptionally powerful negative predictor, but is of little value as a positive predictor of CD in individual patients, because these susceptibility genes are found in 30 to $40 \%$ of the general community. Large-scale, high-throughput HLA-DQ genotyping is now inexpensive in the research setting, but remains surprisingly expensive in some healthcare systems when used in clinical practice.

In the current study, we tested the positive predictive power of HLA-DQ genotyping and serology to estimate the prevalence of $C D$ at a population level. This novel approach has the potential to overcome the limitations imposed by the requirement for intestinal histology to assess population prevalence accurately. Our findings also led us to develop a series of diagnostic algorithms to compare costs and resource utilization, and these could be used to inform clinical decision-making when evaluating the possibility of $\mathrm{CD}$ in patients not considered at high risk. 


\section{Methods}

\section{Study populations}

The community cohorts used in this study have been described previously $[18,19]$. Briefly, subjects were recruited to both female and the male age-stratified, randomly selected cohorts, based on the electoral rolls in the Barwon Statistical Division, a geographically well-defined, large, stable population of 259,013 people (2006 Australian Bureau of Statistics Catalogue number 2001.0) whose educational and socioeconomic characteristics and age structure differ by less than 5\% from the national Australian profiles [19]. Participation rates were $77 \%$ for the female cohort and $65 \%$ for the male cohort. The female cohort was recruited between 1994 and $1997(\mathrm{n}=1494$; median age 54 years, range 20 to 94 years), and the male cohort was recruited between 2001 and 2006 ( $\mathrm{n}=1540$; median age 56 years, range 20 to 97 years). Blood was taken from all participants at enrolment after an overnight fast. Sera that were stored frozen at $-80^{\circ} \mathrm{C}$ for 13 to 16 years (females) or 4 to 9 years (males) were available for 1,390 women and 1,158 men. DNA extracted from whole blood and then stored at $-80^{\circ} \mathrm{C}$ was also available for 1,177 of the women and 1,056 of the men who had provided sera. Frozen sera collected 10 years later were also available from 597 of the 1,390 subjects in the female cohort. Subjects in the female cohort were invited to return every 2 years, and those in the male cohort to return every 5 years. At enrolment and at each review, participants completed questionnaires about their demographics, general health, medication exposure, and disease histories. Medical history was derived from the self-reported history of diseases, and where possible validated by reference to the participants' medical records. In 2010, volunteers whose deidentified data indicated abnormal composite TG2/ deamidated gliadin peptide (DGP) IgG and IgA serology that was then confirmed by raised levels of TG2 IgA, DGP IgG (DGP-G), or DGP IgA (DGP-A) were contacted by letter and informed that their blood tests suggested $C D$, and that although this did not diagnose $\mathrm{CD}$, they ought to see their doctor as soon as possible to discuss appropriate management.

In a separate study, volunteers aged between 18 and 70 years old with 'biopsy-confirmed' $C D$ based on the 1990 ESPGHAN diagnostic criteria [3] were recruited at The Royal Melbourne Hospital following advertisements in the Victorian State Coeliac Society newsletter. HLADQ genotypes were established for these subjects, and these have been partially reported elsewhere [17].

\section{Ethics}

Approval by the appropriate ethics committees was obtained by each of the participating centers. The Barwon Health Human Research and Ethics Committee granted approval for the original prospective community cohorts (92/01 and 00/56). An amendment in 2009 allowed testing for CD (92/01-s5 and 00/56-s5), and The Melbourne Health Human Research Ethics Committee approved recruitment of volunteers with biopsyconfirmed $\mathrm{CD}$ for the study 'Gluten Immunity in Coeliac Disease' (2003.009). Written informed consent was obtained from each volunteer participating in the study.

\section{Serology}

A single clinical diagnostic immunology scientist (RT) performed all serological assays in a commercial pathology laboratory (Healthscope Pathology, Clayton, Victoria, Australia). Sera from 1,390 women ( $95 \%$ of the female cohort) and 1,158 men (98\% of the male cohort) were thawed once, divided into smaller aliquots, and stored at $-80^{\circ} \mathrm{C}$ before being transferred to the clinical laboratory. The thawed sera were tested in batches for anti-native human TG2 IgA (h-tTG IgA; QUANTA Lite $^{\circ}$; product number 708760), anti-gliadin IgG (AGG; QUANTA Lite ${ }^{\circ}$ Gliadin IgG; number 708650), antigliadin IgA (AGA; QUANTA Lite ${ }^{\circ}$ Gliadin IgA; number 708655) (all INOVA Diagnostics Inc., San Diego, CA, USA), and in a composite antigen ELISA that measures IgA and IgG specific for native human red cell-derived TG2 and synthetic, deamidated gliadin-derived peptides (composite TG2/DGP IgA/IgG; QUANTA Lite ${ }^{\circ}$ h-tTG/DGP Screen; number 704575; INOVA Diagnostics Inc.). If the result of the initial TG2 IgA ELISA was at or above the manufacturer's cut-off value of 20 units, then a sample of the same aliquot of serum was also tested for EMA (monkey esophagus IFA Kit; binding site FK208.2/INOVA number I704150; INOVA Diagnostics Inc.). When EMA was negative and TG2 IgA abnormal, the same serum was tested using another commercial TG2 IgA ELISA kit (1910-9601 A; Euroimmun AG, Lubeck, Germany). If the result of the composite TG2/DGP IgA/IgG screen was at or above the manufacturer's upper limit of normal (ULM), that is $20 \mathrm{U}$,) the same sample of serum was tested for TG2 IgA (QUANTA Lite ${ }^{\ominus}$ h-tTG IgA; number 708760), DGP-G (QUANTA Lite ${ }^{\circ}$ Gliadin IgG II; number 704520) and DGP-A (QUANTA Lite ${ }^{\circ}$ Gliadin IgA II; number 704525) (all INOVA Diagnostics Inc.)

\section{HLA-DQ genotyping}

In the community cohort, DNA was extracted from the blood collected at enrolment. Five single-nucleotide polymorphisms (SNPs) (rs2187668, rs2395182, rs4713586, rs7454108, and rs7775228) in linkage disequilibrium with the CD-associated HLA risk factors DQ2.5, DQ8, and DQ2.2, which indicate direct risk, and with DQA1"0505/ DQB1*0301 (DQ7), which contributes to the risk of 
DQ2.5 in CD when also inherited with DQA1*0201/ DQB1*0202 (DQ2.2) were used to determine HLA-DQ haplotypes, as previously described [20,21]. Genotyping was performed by the Human Genetics Group ( $t$ the University of Queensland Diamantina Institute) using Taqman SNP genotyping methods (Applied Biosystems, Foster City, CA, USA) following the manufacturer's protocols. Full SNP-based HLA-DQ genotyping was possible for 1,065 (90\%) of the 1,177 DNA samples provided from the female cohort and 921 (87\%) of the DNA samples from the male cohort; hence, complete HLA-DQ genotype and serology datasets were available for $73 \%$ of the total female cohort and $78 \%$ of the total male cohort. For subjects from the cohort of patients with biopsyconfirmed $\mathrm{CD}$ and for subjects in the community female and male cohorts with higher readings in the composite TG2/DGP IgA/IgG screen, which were subsequently confirmed by increased TG2 IgA, DGP-G or DGP-A levels, the HLA-DQ genotypes were also determined in a clinical immunogenetics laboratory using the PCR to sequence-specific oligonucleotide (SSO) hybridization method (Victorian Transplantation and Immunogenetics Service, Parkville, VIC, Australia) [22-24]. HLADQ2.5, DQ8, and DQ2.2 genotypes determined by both methods for 73 subjects were in agreement, except in 1 case. which was determined to be HLA-DQ2.5 ${ }^{+} \mathrm{DQ}^{-}$ DQ2.2 $2^{-}$by SSO and HLA-DQ2.5 DQ8 ${ }^{-} 2.2^{+}$by SNP genotyping.

\section{Statistical analysis}

The GraphPad Prism software package (GraphPad Software, Inc. La Jolla, CA, USA) was used for statistical calculations. Serological status and HLA-DQ genotype were compared by Fisher's exact test. A probability of less than $5 \%$ by two-tailed analysis was taken to be significant.

For the 1,065 subjects from the female cohort, and 921 subjects from the male cohort with paired HLA-DQ genotype and serology data, the estimated number with $\mathrm{CD}(\mathrm{n})$ was calculated using contingency tables as the excess of subjects found to be positive for one or an indicated series of serological tests and also gene-positive for HLA-DQ2.5, DQ8, or DQ2.2 $\left(\mathrm{a}_{O}\right)$ above those expected $\left(\mathrm{a}_{E}\right)$, minus the difference between the observed $\left(\mathrm{c}_{O}\right)$ and expected $\left(\mathrm{c}_{E}\right)$ number of subjects who were seropositive and genenegative for HLA-DQ2.5, DQ8, and DQ2.2:

$$
\mathrm{n}=\left(\mathrm{a}_{O}-\mathrm{a}_{E}\right)-\left(\mathrm{c}_{O}-\mathrm{c}_{E}\right)
$$

here the expected number of seropositive and genepositive subjects is:

$$
\begin{aligned}
\mathrm{a}_{E}= & \left(\mathrm{a}_{O}+\mathrm{c}_{O}\right) \times\left(\mathrm{a}_{O}+\mathrm{b}_{O}\right) \\
& \div\left(\mathrm{a}_{O}+\mathrm{b}_{O}+\mathrm{c}_{O}+\mathrm{d}_{O}\right)
\end{aligned}
$$

where $b_{O}$ is the observed number of seronegative and gene-positive subjects, and $\mathrm{d}_{O}$ is the observed number of seronegative and of gene-negative subjects. Similarly, the expected number of seropositive and of gene-negative subjects is given by:

$$
\begin{aligned}
\mathrm{c}_{\mathrm{E}}= & \left(\mathrm{a}_{O}+\mathrm{c}_{O}\right) \times\left(\mathrm{c}_{O}+\mathrm{d}_{O}\right) \\
& \div\left(\mathrm{a}_{O}+\mathrm{b}_{O}+\mathrm{c}_{O}+\mathrm{d}_{O}\right)
\end{aligned}
$$

The upper $\left(\mathrm{n}_{U L}\right)$ and lower $\left(\mathrm{n}_{L L}\right) 95 \%$ confidence intervals (CIs) for the estimated numbers of subjects with $\mathrm{CD}$ (n) were derived using equation 1 , and the upper $\left(\mathrm{RR}_{U L}\right)$ and lower $\left(R_{L L}\right)$ 95\% confidence intervals of the relative risk (RR) for being gene-positive in the seropositive subjects were calculated by GraphPad Prism, thus:

$$
\mathrm{RR}=\left(\mathrm{a}_{O} \div\left(\mathrm{a}_{O}+\mathrm{c}_{O}\right)\right) \div\left(\mathrm{b}_{O} \div\left(\mathrm{b}_{O}+\mathrm{d}_{O}\right)\right)
$$

and therefore, the upper 95\% CI for the number of subjects seropositive and gene-positive $\left(\mathrm{a}_{U L}\right)$ is given by:

$$
\mathrm{a}_{U L}=\left(\mathrm{RR}_{U L} \times\left(\mathrm{a}_{O}+\mathrm{c}_{O}\right) \times \mathrm{b}_{O}\right) \div\left(\mathrm{b}_{O}+\mathrm{d}_{O}\right)
$$

Similarly, the lower 95\% CI $\left(\mathrm{a}_{L L}\right)$ for the number of subjects seropositive and gene-positive is given by:

$$
a_{L L}=\left(\mathrm{RR}_{L L} \times\left(\mathrm{a}_{O}+\mathrm{c}_{O}\right) \times \mathrm{b}_{O}\right) \div\left(\mathrm{b}_{O}+\mathrm{d}_{O}\right)
$$

The upper 95\% CI for the number of subjects seropositive and gene-negative $\left(\mathrm{c}_{U L}\right)$ is then:

$$
\mathrm{c}_{U L}=\left(\mathrm{a}_{O}+\mathrm{c}_{O}\right)-\mathrm{a}_{U L}
$$

and similarly, the lower $95 \% \mathrm{CI}$ for the number of subjects seropositive and gene-negative $\left(c_{L L}\right)$ is then:

$$
\mathrm{c}_{L L}=\left(\mathrm{a}_{O}+\mathrm{c}_{O}\right)-\mathrm{a}_{L L}
$$

Thus, the upper $95 \% \mathrm{CI}\left(\mathrm{n}_{U L}\right)$ for the number of subjects with $\mathrm{CD}$ is given by:

$$
\mathrm{n}_{U L}=\left(\mathrm{a}_{U L}-\mathrm{a}_{E}\right)+\left(\mathrm{c}_{E}-\mathrm{c}_{U L}\right)
$$

and the lower $95 \% \mathrm{CI}\left(\mathrm{n}_{L L}\right)$ for the number of cases with $\mathrm{CD}$ is then:

$$
\mathrm{n}_{L L}=\left(\mathrm{a}_{L L}-\mathrm{a}_{E}\right)+\left(\mathrm{c}_{E}-\mathrm{c}_{L L}\right)
$$

\section{Costing of diagnostic algorithms}

Australia has a publicly funded health system that provides primary healthcare treatment for all Australian citizens and permanent residents, and is operated by the government authority Medicare Australia. To estimate the cost of investigations incurred for a hypothetical cohort of 1,000 adult men or women in the community being tested for CD, the full Australian Medicare Benefits Schedule fees were applied (http://www9.health.gov.au/ mbs/search.cfm). The cost code 71163 (A $\$ 1=$ US $\$ 0.91$; A \$24.90) was applied for initial TG2 IgA estimation or composite TG2/DGP IgA/IgG screen; 71164 (A \$40.15) 
for confirmatory EMA (combined with repeat TG2 IgA) or TG2 IgA, DGP-G, and DGP-G; 71151 (A \$119.65) for HLA-DQ genotyping; and an aggregated estimate of $\mathrm{A} \$ 850$ for diagnostic gastroscopy performed in a community endoscopy center by a specialist gastroenterologist, with sedation provided by a medical practitioner sedationist, and standard histology of five biopsies collected from the proximal small intestine. The costs of follow-up appointments with the treating doctor, and personal costs borne by the patient associated with attendance for blood collection and gastroscopy were not included. For the purpose of modeling the effectiveness of the diagnostic algorithms, we assumed that small bowel histology correctly identified all patients with $C D$ predicted by serogenetic prevalence estimates. However, it should be noted that small bowel biopsies collected from approximately $10 \%$ of patients are not suitable for definitive diagnosis, and inter-observer variability between histopathologists can be substantial $[25,26]$. Per capita claims to Medicare Australia for one of two item numbers dedicated to $\mathrm{CD}$ serology testing
(71163 and 71164) were sourced from the website of Medicare Australia (https://www.medicareaustralia.gov. au/statistics/mbs_item.shtml).

\section{Results}

HLA-DQ status and biopsy-confirmed CD

We first determined the prevalence of HLA-DQ2.5, DQ8, or DQ2.2 in local members of the celiac support group who responded to an invitation for volunteers with 'biopsy-proven' CD. Of 356 patients with a diagnosis of CD confirmed by small bowel histology, HLADQ2.5 was present in 325 patients (91.3\%), HLA-DQ8 but not HLA-DQ2.5 was found in 19 (5.3\%), and DQ2.2 but not HLA-DQ2.5 or HLA-DQ8 was present in 7 (2.0\%) (Table 1 ); only 5 patients (1.4\%) lacked HLA-DQ2 .5, HLA-DQ8 and HLA-DQ2.2. Clinical review led to $\mathrm{CD}$ being excluded in four of these 'gene-negative' cases because the small bowel histology remained normal after prolonged gluten challenge, and in two cases because the intestinal histology and further investigations led to a diagnosis of Crohn's disease or common variable

Table 1 Serology, HLA-DQ status, and inferred prevalence of CD

\begin{tabular}{|c|c|c|c|c|c|}
\hline & Total & $\begin{array}{l}\text { HLA-DQ 2.5/8/2.2-positive, } \\
\text { observed,(expected) n }\end{array}$ & $\begin{array}{c}\text { HLA-DQ 2.5/8/2.2-positive, } \\
\text { RR }(95 \% \mathrm{CI})\end{array}$ & $\begin{array}{l}\text { Excess HLA-DQ } \\
\text { 2.5/8/2.2-positive, } \mathrm{n}\end{array}$ & $\begin{array}{l}\text { Prevalence per } \\
1.000(95 \% \mathrm{Cl})\end{array}$ \\
\hline \multicolumn{6}{|c|}{ Biopsy-confirmed CD } \\
\hline$F+M$ & 356 & 351 & $1.78(1.71 \text { to } 1.84)^{\mathrm{a}}$ & & NA \\
\hline \multicolumn{6}{|c|}{ Biopsy-confirmed CD; four of five HLA-DQ2.5-DQ8-DQ2.2- re-investigated } \\
\hline$F+M$ & 352 & 351 & $1.80(1.73 \text { to } 1.89)^{\mathrm{a}}$ & & NA \\
\hline \multicolumn{6}{|c|}{ Community random sample of age-stratified cohorts of adults } \\
\hline $\mathrm{F}$ & 1,065 & 596 & 1 & & 0 \\
\hline M & 921 & 513 & 1 & & 0 \\
\hline \multicolumn{6}{|c|}{ Community sample: initially positive for TG2 IgA } \\
\hline $\mathrm{F}$ & 48 & $34(27)$ & $1.28(1.06 \text { to } 1.55)^{b}$ & 14 & $13.4(2.4$ to 26.8$)$ \\
\hline M & 68 & $44(38)$ & $1.18(0.98 \text { to } 1.42)^{\mathrm{NS}}$ & 12 & $13.2(-2.9$ to 32.8$)$ \\
\hline
\end{tabular}

Community sample: initially positive for TG2 IgA, and confirmed positive for EMA

\begin{tabular}{|c|c|c|c|c|c|}
\hline $\mathrm{F}$ & 13 & $13(7)$ & $1.80(1.71 \text { to } 1.90)^{c}$ & 11 & $10.8(9.5$ to 12.1$)$ \\
\hline M & 13 & $13(7)$ & $1.82(1.71 \text { to } 1.93)^{c}$ & 12 & 12.5 (10.9 to 14.2$)$ \\
\hline
\end{tabular}

Community sample: initially positive for composite TG2/DGP IgA/lgG

$\begin{array}{llllll}\mathrm{F} & 55 & 41(31) & 1.36(1.15 \text { to } 1.60)^{\mathrm{d}} & 20 & 19.2(7.5 \text { to } 32.9) \\ \mathrm{M} & 73 & 46(41) & 1.14(0.95 \text { to } 1.38)^{\mathrm{NS}} & 11 & 11.6(-5.4 \text { to } 32.0)\end{array}$

Community sample: initially positive for composite TG2/DGP IgA/lgG, and confirmed positive for TG2 IgA, DGP-G-+, or DGP-A

$\begin{array}{llllll}\mathrm{F} & 37 & 30(21) & 1.47(1.23 \text { to } 1.74)^{\mathrm{e}} & 19 & 17.5(8.9 \text { to } 27.6) \\ \mathrm{M} & 44 & 29(25) & 1.19(0.96 \text { to } 1.49)^{\mathrm{Ns}} & 9 & 9.8(-2.7 \text { to } 25.3)\end{array}$

Community sample: - initially positive for TG2/DGP IgA/lgG, and confirmed positive for TG2 IgA, DGP-G, and DGP-A

$\begin{array}{llllll}\mathrm{F} & 10 & 10(6) & 1.80(1.71 \text { to } 1.90)^{\mathrm{d}} & 9 & 8.3(7.3 \text { to } 9.3) \\ \mathrm{M} & 11 & 11(6) & 1.82(1.72 \text { to } 1.93)^{\mathrm{e}} & 10 & 10.6(9.3 \text { to } 12.1)\end{array}$

Abbreviations: CD, celiac disease; DGP, Deamidated gliadin-derived peptide; EMA, endomysial immunofluorescence IgA; F, female; HLA, human leukocyte antigen; Ig, immunoglobulin; M, male; NA, not applicable; NS, not significant; RR, relative risk; TG2, transglutaminase-2.

Compared with community $M+F:{ }^{a} P<0.0001$ ( $X^{2}$ two-tailed); ${ }^{b} P<0.04,{ }^{c} P<0.001,{ }^{d} P<0.005$, ${ }^{e} P<0.002$, (Fisher's exact test, two-tailed). 
immunodeficiency. One gene-negative case declined clinical re-evaluation. Hence, at least $99.7 \%$ of local patients with histology-confirmed CD possessed HLADQ2.5, HLA-DQ8, or HLA-DQ2.2.

\section{Community prevalence of celiac disease HLA-DQ susceptibility genotypes}

In the female and male cohorts recruited from the community, $55.9 \%$ and $55.7 \%$ of genotyped subjects, respectively, were genetically susceptible to $C D$ because they were positive for HLA-DQ2.5, DQ8, or DQ2.2. The proportions of the genotyped women and men positive for HLA-DQ2.5 were virtually identical: $24.3 \%$ versus $24.7 \%$, respectively. Subjects negative for HLA-DQ2.5 but positive for HLA-DQ8 accounted for $15.7 \%$ of women and $16.1 \%$ of men; and subjects who were negative for both HLA-DQ2.5 and HLA-DQ8 but positive for HLA-DQ2.2 represented $16.0 \%$ of women and $15.0 \%$ of men. Accordingly, the RR for HLA-DQ2.5, DQ8, or DQ2.2 in patients with CD compared with community subjects was 1.80 (95\% CI 1.71 to 1.90$)$ for women and 1.82 (95\% CI 1.71 193) for men (Table 1).

TG2 IgA serology and genetic evidence of celiac disease in the community

Abnormal TG2 IgA serology was found in 64 of 1,390 women (4.6\%) and 80 of 1,158 men (6.9\%). Although genetic susceptibility to $\mathrm{CD}$ was more common in seropositive women than in the community cohort $(P<0.04)$ and showed a positive though non-significant trend in men, $29 \%$ of the women and $35 \%$ of the men who were seropositive for TG2 IgA were not genetically susceptible to CD (Figure 1A, Table 1). Higher levels of TG2 IgA were more strongly associated with HLA-DQ2.5, DQ8, and DQ2.2, and all 16 subjects with TG2 IgA levels above $85 \mathrm{U}(4.5 \times \mathrm{ULN})$ possessed HLA-DQ2.5 or HLA-DQ8 (Figure 1B). By contrast, genetic susceptibility to $\mathrm{CD}$ was the same in subjects with TG2 IgA levels of 20 to $40 \mathrm{U}(53 \%)$ as it was in seronegative subjects (54\%). Based on the absence of genetic susceptibility to $\mathrm{CD}$ in approximately one-third of subjects with sera showing increased levels TG2 IgA, it was clear that false-positive TG2 IgA findings are common in adults in the community. Hence, TG2 IgA serology alone would substantially overestimate the community prevalence of $\mathrm{CD}$, and in clinical practice would be expected to result in many unnecessary gastroscopies to exclude CD.

These observations prompted us to formalize a simple method using contingency table analysis and RR to estimate the prevalence of CD using CD-associated serology and genetic susceptibility, assuming that all individuals with CD possessed HLA DQ2.5, DQ8, or DQ2.2 (see Statistical analysis). Subsequent analysis focused on 1,065 subjects from the female cohort and 921 from the
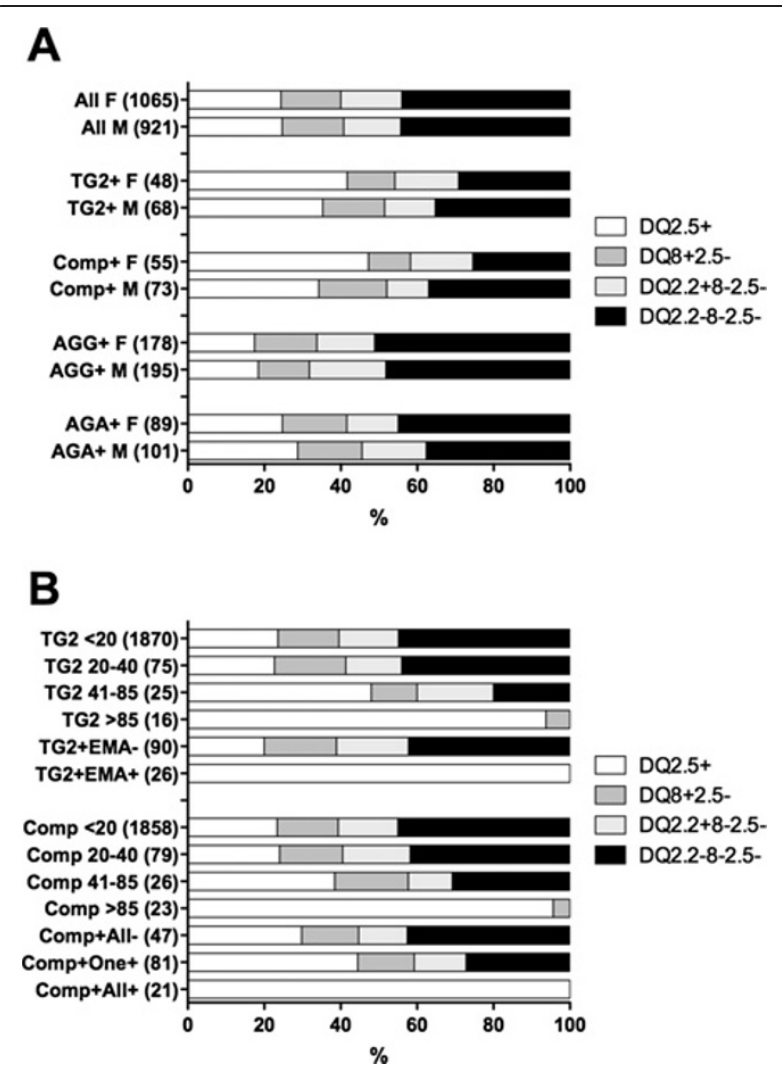

Figure 1 Human leukocyte antigen (HLA-DQ genetic status and celiac disease (CD)-specific serology. (A) HLA-DQ status of female (F) and male (M) community cohorts, and those who tested positive for anti-gliadin IgG (AGG), anti-gliadin IgA (AGA), IgA specific for native human transglutaminase (TG)2, and composite TG2/DGP IgA/ IgG (Comp.). Total numbers of subjects are in brackets. (B) HLA-DQ genotypes of women and men in the combined community cohorts classified by measured level of TG2 IgA and whether endomysial antibody (EMA) was also positive; or composite TG2/ DGP IgA/lgG (Comp.) and whether all or at least one confirmatory serology (TG2 IgA, DGP IgA, or DGP IgG) was abnormal. Numbers of subjects are in brackets. DGP, Deamidated gliadin-derived peptide.

male cohort with both serology and HLA-DQ status determinations. Based on this analysis, the observed enrichment for genetic susceptibility to CD in TG2 IgAseropositive women and men could be accounted for if 14 of 48 seropositive women and 12 of 68 seropositive men had CD. These figures implied that only 14 of 34 women and 12 of 44 men with raised levels of TG2 IgA who possessed HLA-DQ2.5, DQ8, or DQ2.2 were actually affected by $C D$, and that the prevalence of $C D$ was approximately $1.3 \%$ in both the female and male cohorts (Table 1; Figure 2).

To improve the precision of these prevalence estimates, 'confirmatory' EMA tests were performed and found to be positive in 13 women and 13 men with raised TG2 IgA levels. All 26 TG2 IgA+ EMA+ subjects possessed HLA DQ2.5 $(P<0.0001)$. Hence, prevalence 


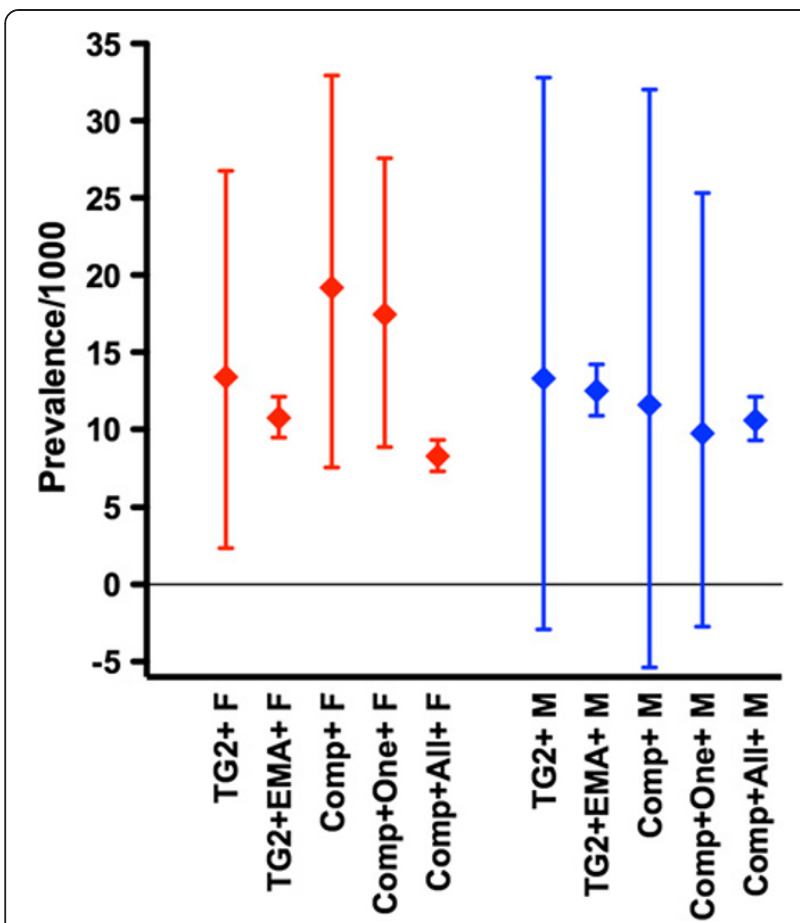

Figure 2 Community prevalence estimates for celiac disease (CD). Estimated prevalence of CD with 95\% confidence intervals per 1,000 adult females (F) or male (M) subjects, based upon enrichment of human leukocyte antigen (HLA)-DQ2.5, DQ8, and DQ2.2 in subjects who were seropositive for transglutaminase (TG)2 IgA (TG2+), TG2 IgA + and then endomysial antibody (EMA)+, composite TG2/DGP IgA/lgG (Comp+), Comp.+ and then TG2 IgA+, deamidated gliadin-derived peptide (DGP)-G+ or DGP-A+ (Comp + One+), and for Comp+ and then TG2 lgA+, DGP-G+ and DGP-A+ (Comp + All+).

estimates for $C D$ based on subjects being positive for both TG2 IgA and EMA were 1.1\% (95\% CI 1.0 to $1.2 \%$ ) in women and $1.3 \%$ (95\% CI 1.1 to $1.4 \%$ ) in men (Table 1 ; Figure 1B; Figure 2).

\section{Expanded serological screening for celiac disease}

It has been hypothesized that there are greater numbers of individuals in the community with genetically determined gluten-mediated disease than just those with raised levels of TG2 IgA or EMA [1,27], and some patients with biopsy-confirmed $\mathrm{CD}$ who are seronegative for TG2 IgA do have raised DGP IgA or IgG levels [28]. IgA and IgG anti-gliadin antibodies (AGA and AGG, respectively) have also been proposed as markers of gluten-responsive irritable bowel syndrome in patients genetically susceptible to $\mathrm{CD}$. When tested in enrolment sera, both AGG and AGA were commonly raised in both the female (17\% and $9 \%$, respectively) and male ( $21 \%$ and $12 \%$, respectively) cohorts, but genetic susceptibility to CD was not significantly increased in AGA or AGG seropositive women (55\% and 49\%, respectively) or men (62\% and 52\%) (Figure 1A).
The composite TG2/DGP IgG/IgA screen was abnormal in 78 of 1,390 women (5.6\%) and 92 of 1,158 men (6.9\%). Women with positive composite TG2/DGP IgG/ IgA screen were more commonly positive for HLA-DQ2.5, DQ8, or DQ2.2 $(75 \%, P<0.005)$ (Table 1 , Figure 1). In men, over-representation of HLA-DQ2.5, DQ8, or DQ2.2 was not as pronounced and did not reach statistical significance $(46 / 73 ; 63 \%)$. As observed with the TG2 IgA serology, higher readings in the composite TG2/DGP IgG/IgA screen were more strongly associated with genetic susceptibility to CD; all 23 subjects with levels above $85 \mathrm{U}(4.5 \times \mathrm{ULM})$ possessed HLADQ2.5 or HLA-DQ8 (Figure 1B). Based upon enrichment for HLA-DQ2.5, DQ8, or DQ2.2 in subjects with raised levels of composite TG2/DGP IgG/IgA, the prevalence of $\mathrm{CD}$ was $1.9 \%$ in women and $1.2 \%$ in men (Table 1; Figure 2). When subjects found to be seropositive by the composite TG2/DGP IgG/IgA screen were tested for TG2 IgA, DGP-G, and DGP-A separately, 65\% (51/78) of women and 61\% (56/92) of men had raised levels in at least one test. Prevalence estimates based on genetic enrichment and 'confirmed' abnormal TG2/DGP IgG/IgA screen were $1.8 \%$ in women and $1.0 \%$ in men (Table 1; Figure 2). All 10 women $(0.9 \%)$ and 11 men $(1.2 \%)$ with raised levels of each of the three serology tests (TG2 IgA, DGP-G, and DGP-A) were HLA-DQ2.5+ $(P<0.0001)$ and also EMA+.

\section{Prospective review in seropositive cases}

There was just one case of biopsy-confirmed CD at enrolment, a 57-year old male who was HLA-DQ2.5+ but negative in the TG2 IgA and composite TG2/DGP IgA/ IgG screens, consistent with a diagnosis of $\mathrm{CD}$ but strictly following a gluten-free diet. Follow-up of the 51 women and 56 men having serum collected at enrolment who had 'confirmed' abnormalities after testing positive in the composite TG2/DGP IgG/IgA screen identified 10 women $(0.7 \%)$ and 6 men $(0.5 \%)$ with intestinal histology showing villous atrophy, crypt hyperplasia, and IELs, confirming active CD (Table 2; see Additional file 1: Tables S1A and S1B). Four of these women and two of these men had been diagnosed with CD between 2004 and 2009 on the basis of typical small bowel histology following investigation for diarrhea $(n=2)$, fatigue $(n=1)$, iron deficiency $(n=1)$, or osteoporosis $(\mathrm{n}=1)$, or after diagnosis of a family member. The other biopsy-confirmed cases resulted from gastroscopies prompted by the current study in 2010. Two biopsy-confirmed cases were in women whose enrolment sera were negative for TG2 IgA, but positive for DGP-G and DGP-A. None of the cases identified with CD were deficient in IgA. Repeat serology after medical review supported CD in two further women (0.1\%) and four additional men $(0.3 \%)$, but these subjects were not 
Table 2 Follow-up and final disposition of subjects ${ }^{a}$

\begin{tabular}{|c|c|c|}
\hline & Women, $\mathrm{n}$ & Men, $\mathbf{n}$ \\
\hline Total subjects & 1,390 & 1,158 \\
\hline CD diagnosed by histology before enrolment & 0 & 1 \\
\hline Abnormal composite TG2/DGP IgA/lgG, and TG2 IgA, or DGP IgA or IgG & 51 & 56 \\
\hline \multicolumn{3}{|l|}{ Findings diagnostic/supportive of untreated CD } \\
\hline \multicolumn{3}{|l|}{ Histological diagnosis: Intestinal villous atrophy, crypt hyperplasia, and IELs } \\
\hline Prompted by current study, 2010 & 6 & 4 \\
\hline During standard medical care between 2004 and 2009 & 4 & 2 \\
\hline \multicolumn{3}{|l|}{ Serological diagnosis: confirmation of multiple CD serological abnormalities } \\
\hline No supporting histological evidence obtained & 2 & 3 \\
\hline Treating doctor excluded CD because patient was asymptomatic & 0 & 2 \\
\hline \multicolumn{3}{|l|}{ Findings equivocal for CD } \\
\hline Intestinal IELs +/- mild focal villous atrophy, or villous atrophy and crypt hyperplasia without IELs & 0 & 3 \\
\hline \multicolumn{3}{|l|}{ Findings excluded/were not supportive of CD } \\
\hline Normal intestinal histology without serological testing & 2 & 5 \\
\hline Serological exclusion: CD serological abnormalities not replicated & 7 & 8 \\
\hline Genotyping exclusion: testing for HLA DQ2.5/8/2.2 negative & 0 & 1 \\
\hline \multicolumn{3}{|l|}{ Follow-up not possible or not undertaken } \\
\hline Treating doctor did not investigate further as subject asymptomatic and/or performed blood tests unrelated to CD & 1 & 5 \\
\hline Subject deceased and CD not diagnosed pre-mortem & 8 & 5 \\
\hline Subject declined follow-up medical review & 16 & 11 \\
\hline Subject could not be contacted; lost to follow-up & 5 & 7 \\
\hline CD cases estimated by serogenetic modeling, range & 12 to 26 & 12 to 16 \\
\hline Lower $95 \% \mathrm{Cl}$ for CD cases based on TG2+ EMA+ & 11 & 12 \\
\hline
\end{tabular}

Abbreviations: CD, celiac disease; DGP, Deamidated gliadin-derived peptide; EMA, endomysial antibody; HLA, human leukocyte antigen; IEL, Intra-epithelial lymphocyte; Ig, immunoglobulin; TG, transglutaminase.

${ }^{a}$ Data are $n$, unless otherwise stated.

investigated further, and the possibility of $C D$ was rejected in two of these cases because the clinician judged that no symptoms suggestive of $C D$ were present. Hence, 12 women $(0.9 \%)$ and 11 men $(0.9 \%)$ with abnormal serology at enrolment had the diagnosis of $\mathrm{CD}$ confirmed by histology or had repeat serology consistent with $\mathrm{CD}$. In addition, three cases had equivocal changes on intestinal histology. In 9 women and 14 men, CD was excluded by serology, HLA-DQ genetic testing, or histology findings. Medical review was not possible for 29 women and 23 men, and in 6 subjects, medical follow-up led to exclusion of $\mathrm{CD}$ without further relevant investigations.

Sera collected from 597 women at the 10-year review showed that $24(4.0 \%)$ had persistent increases in the composite TG2/DGP IgA/IgG and/or TG2 IgA screen; 22 of these subjects had known genotype, and of these, 21 (95\%) were genetically susceptible to CD (see Additional file 2: Table S2). At the 10-year review, serological abnormalities persisted in all genetically susceptible subjects whose enrolment sera had showed a composite TG2/DGP IgA/IgG result of $59 \mathrm{U}$ or higher $(\mathrm{n}=13)$ or TG2 IgA of
$58 \mathrm{U}$ or higher $(\mathrm{n}=11)$. Less pronounced increases in the composite TG2/DGP IgA/IgG and TG2 IgA screens at enrolment were less often reproduced at the 10-year review. There were three cases showing abnormalities in both composite TG2/DGP IgA/IgG and TG2 IgA screens at 10-year follow-up that were not present at enrolment, in two cases EMA was reported as negative and in one it was equivocal (see Additional file 2: Table S2). Both of the genotyped cases showing new serological abnormalities at 10-year follow-up were genetically susceptible to $\mathrm{CD}$. Intestinal histology was not available for these three patients.

\section{Diagnostic pathways}

Prompted by the observed high rate of false-positive serology tests, we designed a series of diagnostic algorithms using either TG2 IgA or composite TG2/DGP IgA/IgG screens or HLA-DQ genotyping as the initial screen, with or without subsequent confirmatory serology and/ or HLA-DQ genotyping prior to gastroscopy and definitive small bowel histology (Table 3). The overall cost and resource utilization of models were compared using the 
Table 3 Models for initial and confirmatory testing of CD

\begin{tabular}{|c|c|c|c|}
\hline Model & Initial test & Additional tests if initial test positive & Definitive test \\
\hline A & TG2 $\lg A$ & None & Biopsy \\
\hline B & TG2 $\lg A$ & HLA-DQ & Biopsy if HLA-DQ2.5/2.2/8+ \\
\hline C & TG2 lgA & EMA and HLA-DQ & Biopsy if HLA-DQ2.5/2.2/8+ \\
\hline D & $\mathrm{TG} 2 \lg \mathrm{A}$ & $\begin{array}{l}\text { If TG2 IgA }>10 \times U L N \text {, then EMA and HLA-DQ; } \\
\text { otherwise none }\end{array}$ & $\begin{array}{l}\text { None if TG2 } \lg A>10 \times U L N \text {, EMA abnormal and HLA-DQ2.5/2.2/8 } \\
+ \text { +; otherwise biopsy }\end{array}$ \\
\hline$E$ & HLA-DQ & TG2 IgA; if TG2 IgA 1 to $3 \times$ ULN, then EMA & Biopsy if TG2 IgA $>3 \times$ ULN or EMA abnormal \\
\hline $\mathrm{F}$ & $\begin{array}{l}\text { Composite TG2/DGP } \\
\text { lgA/lgG }\end{array}$ & None & Biopsy \\
\hline G & $\begin{array}{l}\text { Composite TG2/DGP } \\
\text { lgA/lgG }\end{array}$ & HLA-DQ & Biopsy \\
\hline $\mathrm{H}$ & $\begin{array}{l}\text { Composite TG2/DGP } \\
\text { lgA/lgG }\end{array}$ & HLA-DQ, TG2 IgA, DGP-G and DGP-A & $\begin{array}{l}\text { Biopsy if HLA-DQ2.5/2.2/8+ and either TG2 IgA or DGP-G or } \\
\text { DGP-A abnormal }\end{array}$ \\
\hline
\end{tabular}

Abbreviations: DGP, Deamidated gliadin-derived peptide; EMA, endomysial antibody; HLA, human leukocyte antigen; TG, transglutaminase; ULN, upper limit of normal.

serology and genotyping datasets generated from the female and male cohorts. We assumed that the total numbers of affected cases were those predicted by genetic enrichment in TG2 IgA or composite TG2/DGP IgA/ IgG screen-positive subjects (13/1,000 women and 13/ 1,000 men, and 19/1,000 women and 12/1,000 men, respectively) (Table 4). Because many cases now tested for $\mathrm{CD}$ in Australia occur in the setting of primary care, where the pre-test probability of $\mathrm{CD}$ is unlikely to be substantially different from background community prevalence, this analysis may be relevant to community clinical practice.

Model A (initial testing for TG2 IgA followed by small bowel biopsy) is widely recommended in clinical guidelines, but according to the Medicare Australia item costs, is more expensive and results in more (unnecessary) gastroscopies than the model (model B) including HLA-DQ genotyping to exclude 'gene-negative' TG2 IgA false-positive patients prior to biopsy. Including both confirmatory EMA and HLA-DQ genotyping for TG2 IgA-seropositive patients, but still performing gastroscopies in all of this patient group (model C) modestly increases cost and has the advantage that cases with a pre-biopsy likelihood of CD greater than $90 \%$ can be identified to minimize the risk of biopsy falsenegatives. Model D is based on that proposed by the revised ESPGHAN 2012 criteria for symptomatic children, avoiding the requirement for biopsy in patients with TG IgA levels greater than $10 \times$ ULN who have confirmatory EMA and HLA-DQ genotyping. Only $0.2 \%$ of men and $0.3 \%$ of women in the community would be expected to have levels of TG2 IgA above $10 \times \mathrm{ULN}$, and model D was little different from model $\mathrm{A}$ in its cost and clinical impact. Model $\mathrm{E}$ is based on that proposed by the revised ESPGHAN 2012 criteria for asymptomatic children at increased risk; the initial test is HLA-DQ genotyping followed by biopsy if TG2 IgA is greater than
$3 \times \mathrm{ULN}$, or if TG2 IgA is raised but is less than $3 \times \mathrm{ULN}$ then confirmatory EMA is performed, and if positive, then biopsy is undertaken. The cost associated with model $\mathrm{E}$ is about double that of the next most expensive model, but requires the least number of gastroscopies. Model E is the same as model A except that the composite TG2/DGP IgA/IgG screen is substituted for TG2 IgA; it is cheaper than model A per case diagnosed as it detects additional affected female patients who might be TG2 IgA-seronegative. Including 'confirmatory' HLA-DQ genotyping also reduces the cost of initial testing with the composite TG2/DGP IgA/IgG screen (model G), as it did for TG2 IgA screening in model B. Finally, in model $\mathrm{H}$, biopsies are performed only in patient with positive results on composite TG2/DGP IgA/IgG screen who are confirmed to be genetically susceptible to $C D$ and who also show abnormalities in confirmatory TG2 IgA, DGP-G or DGP-A tests. Model H reduced the cost per case diagnosed by $38 \%$ in women and $25 \%$ in men, and reduced the number of gastroscopies by $38 \%$ in women and $65 \%$ in men.

\section{Discussion}

The concept of a 'celiac iceberg' has been important in drawing attention to a large, unrecognized group of patients with CD who do report symptoms considered 'typical' of CD [29]. Investigators have proposed expansion of the 'iceberg' to encompass patients who are genetically susceptible to $\mathrm{CD}$, but show only raised IEL counts or an isolated abnormal CD-specific serology and normal intestinal histology [30-32]. Consequently, there is considerable uncertainty regarding the true extent of gluten-mediated disease in the community. The recent revision of diagnostic criteria proposed by the ESPGHAN Working Group seeks to address these developments, and increase the contribution of serology and HLA-DQ genetic tests to diagnosis [33-36]. 
Table 4 Models of diagnosis: ${ }^{a}$ overall cost ${ }^{b}$ and numbers of investigations for screening 1,000 adult men or women in the community for $C D$

\begin{tabular}{|c|c|c|c|c|c|c|c|c|c|}
\hline \multirow[t]{2}{*}{ Screen } & \multirow[t]{2}{*}{ Sex } & \multicolumn{8}{|c|}{ Model } \\
\hline & & A & B & $\mathrm{C}$ & D & $\mathrm{E}$ & $\mathbf{F}$ & G & $\mathrm{H}$ \\
\hline \multirow[t]{2}{*}{$T G 2 \lg A^{c}$} & $\mathrm{~F}$ & 1,000 & 1,000 & 1,000 & 1,000 & - & - & - & - \\
\hline & M & 1,000 & 1,000 & 1,000 & 1,000 & - & - & - & - \\
\hline \multirow[t]{2}{*}{ Composite TG2/DGP $\operatorname{lgA} / \operatorname{lgG}^{c}$} & $\mathrm{~F}$ & - & - & - & - & - & 1,000 & 1,000 & 1,000 \\
\hline & M & - & - & - & - & - & 1,000 & 1,000 & 1,000 \\
\hline \multirow[t]{2}{*}{$\mathrm{HLA}^{-D Q^{d}}$} & $\mathrm{~F}$ & - & - & - & - & 1,000 & - & - & - \\
\hline & M & - & - & - & - & 1,000 & - & - & - \\
\hline \multicolumn{10}{|c|}{ Confirmatory test if initial test is 'positive' } \\
\hline \multirow[t]{2}{*}{$\mathrm{TG} 2 \lg \mathrm{A}^{\mathrm{c}}$} & $\mathrm{F}$ & - & - & - & - & 560 & - & - & - \\
\hline & M & - & - & - & - & 557 & - & - & - \\
\hline \multirow[t]{2}{*}{$E M A^{c}$} & $\mathrm{~F}$ & - & - & 45 & 3 & 19 & - & - & - \\
\hline & M & - & - & 69 & 2 & 37 & - & - & - \\
\hline \multirow[t]{2}{*}{ TG2 IgA and DGP-G, DGP-A } & $\mathrm{F}$ & - & - & - & - & - & - & - & 52 \\
\hline & M & - & - & - & - & - & - & - & 79 \\
\hline \multirow[t]{2}{*}{ HLA-DQ ${ }^{d}$} & $\mathrm{~F}$ & - & 45 & 45 & 3 & - & - & 52 & 52 \\
\hline & M & - & 69 & 69 & 2 & - & - & 79 & 79 \\
\hline \multicolumn{10}{|c|}{ Biopsy if initial and/or confirmatory tests are positive ${ }^{f}$} \\
\hline \multirow[t]{2}{*}{ Biopsy } & $\mathrm{F}$ & 45 & 32 & 32 & 42 & 18 & 52 & 38 & 28 \\
\hline & M & 69 & 45 & 45 & 67 & 16 & 79 & 48 & 24 \\
\hline \multirow[t]{2}{*}{ Cases diagnosed ${ }^{g}$} & $\mathrm{~F}$ & 13 & 13 & 13 & 13 & 13 & 19 & 19 & 19 \\
\hline & M & 13 & 13 & 13 & 13 & 13 & 12 & 12 & 12 \\
\hline \multirow[t]{2}{*}{ Total cost for investigations, $\mathrm{A} \$$} & $\mathrm{~F}$ & 63,150 & 57,484 & 58,605 & 61,034 & 149,367 & 69,100 & 63,422 & 57,010 \\
\hline & M & 83,550 & 71,406 & 73,124 & 82,139 & 148,041 & 92,050 & 75,152 & 57,924 \\
\hline \multirow[t]{2}{*}{ Cost per case screened, A\$ } & $\mathrm{F}$ & 63 & 57 & 59 & 61 & 149 & 69 & 63 & 57 \\
\hline & M & 84 & 71 & 73 & 82 & 148 & 92 & 75 & 58 \\
\hline \multirow[t]{2}{*}{ Cost per case diagnosed, $\mathrm{A} \$$} & $\mathrm{~F}$ & 4,858 & 4,422 & 4,508 & 4,695 & 11,490 & 3,637 & 3,338 & 3,001 \\
\hline & M & 6,427 & 5,493 & 5,625 & 6,318 & 11,388 & 7,671 & 6,263 & 4,827 \\
\hline
\end{tabular}

Abbreviations: CD, celiac disease; DGP, Deamidated gliadin-derived peptide; EMA, endomysial antibody; HLA, human leukocyte antigen; TG, transglutaminase. ${ }^{\mathrm{a}}$ Data are $\mathrm{n}$, unless otherwise stated.

${ }^{b}$ Costs are based on $100 \%$ reimbursement of Australian Medicare Benefits Schedule fee for items ${ }^{\mathrm{C}} 71163: \mathrm{A} \$ 24.90,{ }^{\mathrm{d}} 71151: \mathrm{A} \$ 119.65,{ }^{\mathrm{e}} \mathbf{7 1 1 6 4 :} \mathrm{A} \$ 40.15$, and ${ }^{\mathrm{f}} \mathrm{A} \$ 850$ estimated costs of gastroscopy, histology, sedation, and hospital/clinic facility fee.

${ }^{9}$ Cases diagnosed were assumed to be the excess of HLA-DQ2.5/8/2.2 subjects in those screened by TG2 IgA (models A to E), or composite antigen ELISA (model $\mathrm{F}$ to $\mathrm{H})$, as detailed in Table 1.

However, Walker et al. highlighted the difficulties in defining the community prevalence of $\mathrm{CD}$ [1]. From 1,000 randomly selected Swedish adults who underwent diagnostic gastroscopy, 33 were TG2 IgA-positive, and 16 of these were also EMA-positive. These 16 subjects who were seropositive for both TG2 IgA and EMA were considered to have $\mathrm{CD}$, but only 12 of the 16 EMA subjects showed both villous atrophy and increased density of IELs; of the other 4 patients, 3 showed only increased IELs and the fourth had normal histology. In addition, two of the TG2 IgA+ EMA- subjects also showed partial villous atrophy and raised IEL numbers. Walker et al. speculated that if increased TG2 IgA with normal intestinal histology or raised IEL numbers without increased
TG2-IgA reflected gluten-mediated pathology, then the community prevalence of $\mathrm{CD}$ might be considerably greater than their estimate of almost $2 \%$ [1].

Consistent with a previous study from Australia and several from Europe and North America [14,20,37,38], over $98 \%$ of locally recruited volunteers with 'biopsyconfirmed' CD possessed HLA-DQ2.5, DQ8, or DQ2.2. In addition, we found that absence of HLA-DQ2.5, DQ8, or DQ2.2 in 'biopsy-confirmed' cases predicted incorrect diagnosis. Building upon this observation, we developed a novel method to estimate the prevalence of $\mathrm{CD}$ in two large age-stratified, randomly selected community cohorts, based on the relative enrichment for HLA-DQ alleles conveying genetic susceptibility to CD 
in the group of individuals with abnormal CD-specific serology tests. If, as some previous studies have done, we had assumed that all TG2 IgA-seropositive individuals with HLA-DQ2.5, DQ8, or DQ2.2 did have CD, then we would have estimated community prevalence to be $3.1 \%$ in women and $4.8 \%$ in men. The novel serogenetic approach we developed potentially overcomes not only the need for biopsy but also performance variation between different TG2 IgA ELISAs when estimating the prevalence of $\mathrm{CD}$ in the community. In this study, we estimated that $1.3 \%$ of men and women in the community had unrecognized CD using TG2 IgA serology. However, our finding that two TG2 IgA-seronegative women who were positive in the composite TG2/DGP IgA/IgG screen were subsequently confirmed to have $\mathrm{CD}$ on small bowel histology added support to the higher prevalence figure of $1.9 \%$ for women, estimated using the composite TG2/DGP IgA/IgG screen.

Clinical follow-up confirmed 10 new cases of unrecognized $\mathrm{CD}$ in addition to 7 cases diagnosed through standard medical care before or during the current prospective study. As anticipated, the biopsy-confirmed prevalence of $\mathrm{CD}$ of $0.7 \%$ in women and $0.6 \%$ in men was substantially less than by the serogenetic method. However, for a variety of reasons, seven additional cases with persistent serological abnormalities did not undergo gastroscopy, and more than half of the cases who were positive in the composite TG2/DGP IgA/IgG screen were not available for follow-up or had no additional investigation. Medical review of seropositive subjects by their primary care physicians also highlighted the persisting misconception that $\mathrm{CD}$ only presents with classical symptoms. Although use of a gluten-free diet has become much more popular since the enrolment sera were collected, none of the subjects with raised CD-specific serology reported having adopted gluten-free diet, apart from those actually diagnosed with $\mathrm{CD}$. However, it is possible that deliberate or inadvertent reduction of dietary gluten by some formerly seropositive subjects could have resulted in normalization of serological abnormalities.

Testing for $\mathrm{CD}$ is increasing. Claims for serological testing for $\mathrm{CD}$ reimbursed by Medicare Australia in the State of Victoria rose from 9.3 per 1,000 population in 2004 to 14.4 per 1,000 population in 2009 ; the total number of claims during this 6-year period was 72.4 per 1,000 population. Females and males aged over 15 years accounted for $63 \%$ and 23\%, respectively, of all Medicare claims for coeliac disease serology tests in 2010. Between 2004 and 2009, 4 of the estimated 12 to 26 unrecognized cases of CD in our female cohort and 2 of the estimated 12 to 16 unrecognized cases in our male cohort were diagnosed through standard medical care. Over time, as testing increases, the total number of undiagnosed adult cases of $\mathrm{CD}$ would be expected to fall steadily, particularly in women. The combined effects of increased testing and increased diagnoses would eventually reduce the pre-test probability of $\mathrm{CD}$ when testing patients in primary care. TG2 IgA serology is widely recommended as the initial investigation when $\mathrm{CD}$ is considered, but based on serogenetic data from the current study, fewer than one in three women and one in five men with abnormal TG2 IgA in the community would be expected to have unrecognized CD. Hopper et al. also reported similarly high rates of false positives using a different TG2 IgA assay in a group of 2,000 patients referred for gastroscopy [8]. If gastroscopy with intestinal biopsy continues to be recommended as the next step after positive TG2 IgA serology, many unnecessary gastroscopies will be performed, at considerable expense and inconvenience for patients.

To address this problem, we modeled the practical and financial effects of including confirmatory serology and genetic testing after initial testing and before 'definitive' small bowel histology. Inclusion of genetic testing after either TG2 IgA or composite TG2/DGP IgA/IgG serology reduced gastroscopies and overall costs incurred according to the current Medicare Australia reimbursement schedule. Inclusion of confirmatory serology after initial testing with composite TG2/DGP IgA/ IgG serology had a similar effect by reducing gastroscopies without appreciably affecting detection rates, and also lowering overall costs according to pricings in Australia. The applicability and financial effect of the diagnostic algorithms are likely to vary between countries and healthcare systems, depending on local laboratory facilities and costing. However, the community rates of 'positive' and 'negative' serologies and the genetic susceptibility data presented in the current study can be combined with relevant local costs for laboratory assays and procedures to predict which diagnostic pathway might be the most relevant and cost-effective in a particular setting.

Although it would be premature to formally propose a 'single' diagnostic flow chart, the present study highlights the effects of separating initial laboratory testing by serology from a second set of laboratory tests in order to further increase the likelihood of $\mathrm{CD}$ before proceeding to endoscopic biopsy and histology, which is definitive but also the most expensive and intrusive investigation used in diagnostic investigations for CD. Shifting costs from gastroscopy to laboratory testing promises to reduce overall costs and may be more acceptable to patients, particularly if gastroscopy is difficult to access or even undesirable.

\section{Conclusions}

The exceptional performance characteristics of CDspecific serology and HLA-DQ genetic testing have 
prompted the release of new serogenetic criteria to diagnose $\mathrm{CD}$. In the current study, a novel serogenetic methodology was developed to formally estimate the community prevalence of $\mathrm{CD}$ by optimizing combined serological and genetic testing. In contrast to conflicting reports that the prevalence of $\mathrm{CD}$ is overestimated or underestimated due to discordance in intestinal histology and TG2-IgA serology, screening using TG2-IgA, EMA, and HLA-DQ genetic testing indicates that the prevalence of $\mathrm{CD}$ in adults is at least $1.1 \%$ in men and $1.0 \%$ in women, but when TG2 and DGP serology are combined as initial screening tools, sensitivity is improved, and the estimated prevalence of $\mathrm{CD}$ is $1.2 \%$ or $1: 86$ in men and $1.9 \%$ or 1:52 in women. Serogenetic screening without the requirement for follow-up small bowel biopsies provides a flexible, cost-effective methodology that could be widely applied to obtain accurate estimates of the prevalence of $\mathrm{CD}$ in large cohort studies.

In the current study, the serogenetic screening also highlighted that false-positive TG2-IgA serology is common in adults at average risk of CD. Using serology and genetic tests after initial serology screening is both costeffective and could avoid many unnecessary gastroscopies prompted by abnormal 'CD-specific' serology.

\section{Additional files}

Additional file 1: Tables S1. (A) Baseline serogenetic findings and follow-up in females with confirmed abnormal transglutaminase 2/ deamidated gliadin peptide (TG2/DGP) lgA/lgG when recruited 1994 to 1997. (B) Baseline serogenetic findings and follow-up in men with confirmed abnormal composite TG2/DGP IgA/lgG at recruitment during the period 2001 to 2006

Additional file 2: Table S2. Persistent or reproducible abnormal serology in 597 women at baseline and 10 years later.

\section{Abbreviations}

AGA: Anti-gliadin IgA; AGG: Anti-gliadin IgG; CD: Celiac disease; Cl: Confidence interval; DGP: Deamidated gliadin-derived peptides; DGP-A: Deamidated gliadin-derived peptides-immunoglobulin A; DGP-G: Deamidated gliadin-derived peptides-immunoglobulin G; ELISA: Enzyme-linked immunosorbent assay; EMA: Endomysial antibody; ESPGHAN: European Society for Pediatric Gastroenterology, Hepatology, and Nutrition; HLA: Human leukocyte antigen; IEL: Intra-epithelial lymphocyte; lg: Immunoglobulin; PCR: Polymerase chain reaction; RR: Relative risk; SNP: Single-nucleotide polymorphism; SSO: Sequence-specific oligonucleotide; TG: Transglutaminase; ULN: Upper limit of normal.

\section{Competing interests}

RPA is Chief Scientific Officer of ImmusanT Inc., and shareholder in ImmusanT, Inc. and Nexpep Pty Ltd, companies that are directly or indirectly involved in developing treatments and diagnostics for CD. RPA has been a consultant for INOVA Diagnostics, Prometheus Laboratories, and Given Imaging (USA), companies that provide diagnostics for CD. JT-D is a shareholder in Nexpep Pty Ltd., and a consultant to ImmusanT, Inc. RPA and JTD are named inventors on patents related to diagnosis and treatment of CD. The Walter and Eliza Hall Institute of Medical Research hold shares in Nexpep Pty Ltd.

\section{Authors' contributions}

RPA participated in study concept and design, overall supervision, data gathering and analysis, and manuscript preparation; MJH in study design, sample management, data gathering, and manuscript revision; RT in serology assays and manuscript revision; PD in genotyping, data interpretation, and manuscript revision; ELD in study design, genotyping, data interpretation, and manuscript revision; MJC in sample management, data gathering and manuscript revision; KA in sample preparation, and manuscript revision; GCN in study design, supervision, and revision of the manuscript; JTD in study design, data interpretation, and manuscript revision; REK in expert clinical advice and follow-up, and revision of the manuscript; WP and BHT in study design and revision of the manuscript; MAK and MAB in study design, supervision, and revision of the manuscript; and JAP in study design, sample management, data gathering, and manuscript revision. All authors read and approved the final manuscript.

\section{Acknowledgements}

Funding was provided by INOVA Diagnostics Inc., Nexpep Pty Ltd., the NHMRC, the Victorian Health Promotion Foundation, the Geelong Region Medical Research Foundation, the NHMRC Independent Research Institutes Infrastructure Support Scheme (grant number 361646), and Victorian State Government Operational Infrastructure Support. RPA held the lan Mackay Fellowship from the Walter and Eliza Hall Institute and Melbourne Health; JT-D was supported by an NHMRC Postgraduate Medical Scholarship; ELD was funded by an NHMRC Career Development Award (569807); and MAB was funded by an NHMRC Senior Principal Research Fellowship. No funding bodies had any role in study design, data collection and analysis, decision to publish, or preparation of the manuscript. The authors wish to thank the volunteers who participated in this study, and the support of Coeliac Victoria and Tasmania in volunteer recruitment.

\section{Author details}

${ }^{1}$ The Walter and Eliza Hall Institute of Medical Research, 1G Royal Parade, Parkville, Victoria 3052, Australia. ²Department of Medical Biology, The University of Melbourne, Parkville, Victoria 3010, Australia. ${ }^{3}$ Department of Gastroenterology, The Royal Melbourne Hospital, Melbourne Health, Grattan St, Parkville, Victoria 3050, Australia. ${ }^{4}$ Current address: ImmusanT, Inc., ImmusanT Inc., One Kendall Square, Building 200, LL, Suite 4, Cambridge, MA 02139, USA. ${ }^{5}$ School of Medicine, Deakin University, Geelong, Victoria, Australia. ${ }^{6}$ Healthscope Pathology, Melbourne, Victoria, Australia. ${ }^{7}$ Human Genetics Group, University of Queensland Diamantina Institute, Level 5, Translational Research Institute, 37 Kent St, Woolloongabba, QLD 4102, Australia. ${ }^{8}$ Endocrinology, Royal Brisbane and Women's Hospital, Butterfield Rd, Herston, QLD 4029, Australia. ${ }^{9}$ NorthWest Academic Centre, Department of Medicine, The University of Melbourne, St Albans, Victoria, Australia. ${ }^{10}$ Geelong Gastroenterology, Level 1, 83 Myers St, Geelong, Victoria 3220, Australia. ${ }^{11}$ Rural Clinical School, School of Medicine, The University of Queensland, Toowoomba, QLD 4350, Australia. ${ }^{12}$ Current address: Roche Diagnostics Australia, 31 Victoria Avenue, Castle Hill, New South Wales 2154, Australia.

Received: 8 May 2013 Accepted: 2 August 2013

Published: 28 August 2013

\section{References}

1. Walker MM, Murray JA, Ronkainen J, Aro P, Storskrubb T, D'Amato M, Lahr B, Talley NJ, Agreus L: Detection of celiac disease and lymphocytic enteropathy by parallel serology and histopathology in a populationbased study. Gastroenterology 2010, 139:112-119.

2. Biagi F, Klersy C, Balduzzi D, Corazza GR: Are we not over-estimating the prevalence of coeliac disease in the general population? Ann Med 2010, 42:557-561.

3. Walker-Smith J, Guandalini S, Schmitz J, Shmerling D, Visakorpi J: Revised criteria for diagnosis of coeliac disease. Report of working group of European society of paediatric gastroenterology and nutrition. Arch Dis Child 1990, 65:909-911.

4. Husby S, Koletzko S, Korponay-Szabo IR, Mearin ML, Phillips A, Shamir R, Troncone R, Giersiepen K, Branski D, Catassi C, et al: European society for pediatric gastroenterology, hepatology, and nutrition guidelines for the diagnosis of coeliac disease. J Pediatr Gastroenterol Nutr 2012, 54:136-160.

5. National Institute for Health and Clinicial Excellence: NICE Guidelines.; 2009. http://www.nice.org.uk/CG86.

6. Kurppa K, Collin P, Viljamaa M, Haimila K, Saavalainen P, Partanen J, Laurila K, Huhtala H, Paasikivi K, Maki M, et al: Diagnosing mild enteropathy celiac 
disease: a randomized, controlled clinical study. Gastroenterology 2009, 136:816-823.

7. Hopper AD, Hadjivassiliou M, Hurlstone DP, Lobo AJ, McAlindon ME, Egner W, Wild G, Sanders DS: What is the role of serologic testing in celiac disease? A prospective, biopsy-confirmed study with economic analysis. Clin Gastroenterol Hepatol 2008, 6:314-320

8. Hopper AD, Cross SS, Hurlstone DP, McAlindon ME, Lobo AJ, Hadjivassiliou M, Sloan ME, Dixon S, Sanders DS: Pre-endoscopy serological testing for coeliac disease: evaluation of a clinical decision tool. BMJ 2007, 334:729.

9. Maki M, Mustalahti K, Kokkonen J, Kulmala P, Haapalahti M, Karttunen T, Ilonen J, Laurila K, Dahlbom I, Hansson T, et al: Prevalence of Celiac disease among children in Finland. N Engl J Med 2003, 348:2517-2524.

10. Kurppa K, Ashorn M, Iltanen S, Koskinen LL, Saavalainen P, Koskinen O, Maki M, Kaukinen K: Celiac disease without villous atrophy in children: a prospective study. J Pediatr 2010, 157:373-380.

11. Chin MW, Mallon DF, Cullen DJ, Olynyk JK, Mollison LC, Pearce CB: Screening for coeliac disease using anti-tissue transglutaminase antibody assays, and prevalence of the disease in an Australian community. Med J Aust 2009, 190:429-432.

12. Hovell CJ, Collett JA, Vautier G, Cheng AJ, Sutanto E, Mallon DF, Olynyk JK, Cullen DJ: High prevalence of coeliac disease in a population-based study from western Australia: a case for screening? Med J Aust 2001, 175:247-250.

13. Henderson KN, Tye-Din JA, Reid HH, Chen Z, Borg NA, Beissbarth T, Tatham A, Mannering SI, Purcell AW, Dudek NL, et al: A structural and immunological basis for the role of human leukocyte antigen DQ8 in celiac disease. Immunity 2007, 27:23-34.

14. Karell K, Louka AS, Moodie SJ, Ascher H, Clot F, Greco L, Ciclitira PJ, Sollid LM, Partanen J, European Genetics Cluster on Celiac D: HLA types in celiac disease patients not carrying the $\mathrm{DQA} 1{ }^{*} 05-\mathrm{DQB} 1{ }^{*} 02(\mathrm{DQ} 2)$ heterodimer: results from the European Genetics Cluster on Celiac Disease. Hum Immunol 2003, 64:469-477.

15. Lundin KE, Scott H, Fausa O, Thorsby E, Sollid LM: T cells from the small intestinal mucosa of a DR4, DQ7/DR4, DQ8 celiac disease patient preferentially recognize gliadin when presented by DQ8. Hum Immunol 1994, 41:285-291.

16. Lundin KE, Scott H, Hansen T, Paulsen G, Halstensen TS, Fausa O, Thorsby E, Sollid LM: Gliadin-specific, HLA-DQ(alpha $1{ }^{*} 0501$, beta $1{ }^{*} 0201$ ) restricted $T$ cells isolated from the small intestinal mucosa of celiac disease patients. J Exp Med 1993, 178:187-196.

17. Tye-Din JA, Stewart JA, Dromey JA, Beissbarth T, van Heel DA, Tatham A, Henderson K, Mannering SI, Gianfrani C, Jewell DP, et al: Comprehensive, quantitative mapping of $\mathrm{T}$ cell epitopes in gluten in celiac disease. Sci Transl Med 2010, 2:41ra51.

18. Pasco JA, Nicholson GC, Kotowicz MA: Cohort profile: Geelong osteoporosis study. Int J Epidemiol 2012, 41:1565-1575.

19. Henry MJ, Pasco JA, Nicholson GC, Seeman E, Kotowicz MA: Prevalence of osteoporosis in Australian women: Geelong Osteoporosis Study. J Clin Densitom 2000, 3:261-268.

20. Koskinen L, Romanos J, Kaukinen K, Mustalahti K, Korponay-Szabo I, Barisani D, Bardella MT, Ziberna F, Vatta S, Szeles G, et al: Cost-effective HLA typing with tagging SNPs predicts celiac disease risk haplotypes in the Finnish, Hungarian, and Italian populations. Immunogenetics 2009, 61:247-256.

21. Monsuur AJ, de Bakker PI, Zhernakova A, Pinto D, Verduijn W, Romanos J, Auricchio R, Lopez A, van Heel DA, Crusius JB, et al: Effective detection of human leukocyte antigen risk alleles in celiac disease using tag single nucleotide polymorphisms. PLOS ONE 2008, 3:e2270

22. Mullighan CG, Bunce $M$, Welsh Kl: High-resolution HLA-DQB1 typing using the polymerase chain reaction and sequence-specific primers. Tissue Antigens 1997, 50:688-692.

23. Bunce $M, O^{\prime}$ Neill CM, Barnardo MC, Krausa P, Browning MJ, Morris PJ, Welsh Kl: Phototyping: comprehensive DNA typing for HLA-A, B, C, DRB1, DRB3, DRB4, DRB5 \& DQB1 by PCR with 144 primer mixes utilizing sequence-specific primers (PCR-SSP). Tissue Antigens 1995, 46:355-367.

24. Olerup O, Aldener A, Fogdell A: HLA-DQB1 and -DQA1 typing by PCR amplification with sequence-specific primers (PCR-SSP) in 2 hours. Tissue Antigens 1993, 41:119-134.

25. Arguelles-Grande C, Tennyson CA, Lewis SK, Green PH, Bhagat G: Variability in small bowel histopathology reporting between different pathology practice settings: impact on the diagnosis of coeliac disease. J Clin Pathol 2012, 65:242-247.
26. Collin P, Kaukinen $\mathrm{K}$, Vogelsang H, Korponay-Szabo I, Sommer R, Schreier E, Volta U, Granito A, Veronesi L, Mascart F, et al: Antiendomysial and antihuman recombinant tissue transglutaminase antibodies in the diagnosis of coeliac disease: a biopsy-proven European multicentre study. Eur J Gastroenterol Hepatol 2005, 17:85-91.

27. Wahnschaffe U, Ullrich R, Riecken EO, Schulzke JD: Celiac disease-like abnormalities in a subgroup of patients with irritable bowel syndrome. Gastroenterology 2001, 121:1329-1338.

28. Sugai E, Hwang HJ, Vazquez H, Smecuol E, Niveloni S, Mazure R, Maurino E, Aeschlimann P, Binder W, Aeschlimann D, et al: New serology assays can detect gluten sensitivity among enteropathy patients seronegative for anti-tissue transglutaminase. Clin Chem 2010, 56:661-665.

29. Catassi C, Ratsch IM, Fabiani E, Rossini M, Bordicchia F, Candela F, Coppa GV, Giorgi PL: Coeliac disease in the year 2000: exploring the iceberg. Lancet 1994, 343:200-203.

30. Tosco A, Salvati VM, Auricchio R, Maglio M, Borrelli M, Coruzzo A, Paparo F, Boffardi M, Esposito A, D'Adamo G, et al: Natural history of potential celiac disease in children. Clin Gastroenterol Hepatol 2011, 9:320-325.

31. Sperandeo MP, Tosco A, Izzo V, Tucci F, Troncone R, Auricchio R, Romanos J, Trynka G, Auricchio S, Jabri B, et al: Potential celiac patients: a model of celiac disease pathogenesis. PLOS ONE 2011, 6:e21281.

32. Troncone R, Greco L, Mayer M, Paparo F, Caputo N, Micillo M, Mugione P, Auricchio S: Latent and potential coeliac disease. Acta Paediatr Supp/ 1996, 412:10-14.

33. Schwertz E, Kahlenberg F, Sack U, Richter T, Stern M, Conrad K, Zimmer KP Mothes T: Serologic assay based on gliadin-related nonapeptides as a highly sensitive and specific diagnostic aid in celiac disease. Clin Chem 2004, 50:2370-2375.

34. Kaukinen K, Partanen J, Maki M, Collin P: HLA-DQ typing in the diagnosis of celiac disease. Am J Gastroenterol 2002, 97:695-699.

35. Dieterich W, Laag E, Schopper H, Volta U, Ferguson A, Gillett H, Riecken EO, Schuppan D: Autoantibodies to tissue transglutaminase as predictors of celiac disease. Gastroenterology 1998, 115:1317-1321.

36. Hadithi M, von Blomberg BM, Crusius JB, Bloemena E, Kostense PJ, Meijer JW, Mulder CJ, Stehouwer CD, Pena AS: Accuracy of serologic tests and HLA-DQ typing for diagnosing celiac disease. Ann Intern Med 2007, 147:294-302.

37. Rubio-Tapia A, Van Dyke CT, Lahr BD, Zinsmeister AR, El-Youssef M, Moore SB, Bowman M, Burgart $L$, Melton LJ 3rd, Murray JA: Predictors of family risk for celiac disease: a population-based study. Clin Gastroenterol Hepatol 2008, 6:983-987.

38. Doolan A, Donaghue K, Fairchild J, Wong M, Williams AJ: Use of HLA typing in diagnosing celiac disease in patients with type 1 diabetes. Diabetes Care 2005, 28:806-809.

doi:10.1186/1741-7015-11-188

Cite this article as: Anderson et al: A novel serogenetic approach determines the community prevalence of celiac disease and informs improved diagnostic pathways. BMC Medicine 2013 11:188.

\section{Submit your next manuscript to BioMed Central and take full advantage of:}

- Convenient online submission

- Thorough peer review

- No space constraints or color figure charges

- Immediate publication on acceptance

- Inclusion in PubMed, CAS, Scopus and Google Scholar

- Research which is freely available for redistribution 